\title{
Type D (Distressed) Personality in Lithuanian Patients with Coronary Artery Disease: A Dataset
}

\author{
Dalia Stropute $^{a}(\varangle)$, Adomas Bunevicius ${ }^{b}$, Margarita Staniute $^{a}$, Julija \\ Brozaitiene $^{a}$, Robertas Bunevicius ${ }^{a}$
}

a Behavioral Medicine Institute, Lithuanian University of Health Sciences, Vyduno al. 4, 00135 Palanga, Lithuania http://Ismuni.lt/en/structure/medical-academy-/behavioral-medicine-institute/about-institute/

b Neuroscience Institute, Lithuanian University of Health Sciences, Eiveniu str. 4, LT-50009, Kaunas, Lithuania http://Ismuni.lt/en/structure/medical-academy-/neuroscience-institute/

\section{ARTICLE INFO: \\ ReCEIVED: 09 Oct 2015 \\ REVISED: 12 Nov 2015 \\ ACCEPTED: 30 Nov 2015 \\ ONLINE: 15 Dec 2015}

\section{KEYWORDS:}

anxiety

coronary artery disease

depression

type D Personality

\begin{abstract}
A B STRACT
In recent years, Type D (distressed) personality was introduced as a vulnerability factor for general psychological distress in patients with coronary artery disease. The 14-item Type D personality Scale (DS14) was specifically developed to assess negative affectivity and social inhibition, and currently is the most widely used instrument to identify patients with a Type D profile. The goals of this study were to examine: (1) the validity of the Type D construct and its assessment with the DS14 in Lithuania; (2) the prevalence of Type D personality in Lithuanian patients with coronary artery disease; and (3) the association of Type $D$ personality with an increased vulnerability for anxiety and depression in these patients.

Here we present a dataset from prospective observational cohort study of 543 consecutive patients (388 men and 155 women; mean age $58 \pm 9$ years) diagnosed with coronary artery disease and attending a rehabilitation program. The dataset includes socio-demographic and clinical characteristics, assessment of Type D personality, assessment of symptoms of anxiety and depression and assessment of Big-Five personality traits.
\end{abstract}

\section{Overview}

Psychological distress is associated with development and progression of coronary artery disease (CAD), and is closely related to clinical outcomes of patients with CAD. ${ }^{1-3}$ In recent years, Type D (distressed) personality trait was introduced as a vulnerability factor for general psychological distress and was linked to poor clinical and patient oriented outcomes among patients with established diagnosis of CAD. ${ }^{4}$

Type $D$ personality trait refers to a combination of high levels of negative affectivity (NA; tendency 
to experience negative emotions) and social inhibition (SI; tendency to inhibit self-expression in social interactions). ${ }^{5}$ Both NA and $\mathrm{SI}$ are considered normal and stable personality traits, whereas mood disorders refer to pathologic conditions that tend to be episodic and are affected by environmental factors. ${ }^{6}$ In patients with CAD, Type D personality has been associated with an increased risk of cardiovascular events, ${ }^{4}$ poor health related quality of life, ${ }^{7}$ high levels of fatigue ${ }^{8}$ and behavioural risk factors for CAD progression, such as poor medication adherence. ${ }^{9}$ In addition, it has been documented that Type $D$ personality trait carries an increased risk for development of mental disorders, such as depression and anxiety, ${ }^{10}$ thereby increasing the emotional burden of CAD victims. Importantly, it has been shown that these adverse psychological and somatic effects of Type $D$ personality trait are independent from CAD severity ${ }^{6,11}$ or co-morbid mood and anxiety symptoms. ${ }^{12}$ Thus, it has been suggested that assessment of CAD patients for the presence of Type $D$ personality could aid to identify patients at high risk for poor outcomes. ${ }^{13}$

The 14-item Type D personality Scale (DS14) was specifically developed to assess Type $D$ personality characteristics (NA and $\mathrm{SI}$ ), and currently is the most widely used instrument to identify patients with a Type D profile. ${ }^{5}$ There is ample evidence regarding the validity and feasibility of the DS14 scale for assessment of the Type D construct in Western, ${ }^{14-17}$ and non-Western ${ }^{18-20}$ countries. However, more research is needed to assess cross-cultural validity of the DS14 instruments and to define Type $D$ personality trait as a vulnerability marker for psychological distress in somatic patients. Furthermore, prevalence of Type $D$ personality trait in Lithuania remains to be investigated.

The aims of this study were to examine: (1) the validity of the Type $D$ construct and its assessment with the DS14 in Lithuania; (2) the prevalence of Type D personality in Lithuanian patients with CAD; and (3) the association of Type D personality with an increased vulnerability for anxiety and depression in these patients.

Here we present a dataset from prospective observational cohort study of 543 consecutive patients (388 [72\%] men and 155 [28\%] women; mean age $58 \pm 9$ years) diagnosed with CAD and attending an inpatient rehabilitation program at the Cardiovascular Rehabilitation Clinic of the Behavioral Medicine Institute of the Lithuanian University of Health Sciences in Palanga, Lithuania. The dataset includes socio-demographic and clini- cal characteristics, assessment of Type D personality, assessment of symptoms of anxiety and depression and assessment of Big-Five personality traits. ${ }^{21}$

\section{Methods}

\section{Subjects and Procedure}

Patient inclusion in this prospective observational cohort study was performed at the Cardiovascular Rehabilitation Clinic of the Behavioral Medicine Institute of the Lithuanian University of Health Sciences (LUHS BMI) in Palanga, Lithuania in the period from February 2007 until January 2011. The contingent of the study was consecutive CAD patients attending an inpatient rehabilitation program at the Cardiovascular Rehabilitation Clinic of the LUHS BMI. Only patients who agreed to participate in this study and signed written informed consent form were included.

The study and its consent procedures were approved by the Ethics Committee for Biomedical Research at Lithuanian University of Health Sciences, Kaunas, Lithuania. A written informed consent was obtained from each study patient.

All study patients were admitted to the rehabilitation program within one week after discharge from cardiology inpatient unit following treatment for acute coronary syndromes. Inpatient treatment lasted for about one week. Thus, patients were included in this study approximately two weeks after acute myocardial infarction (MI) or an episode of chest angina. All study patients were receiving standard treatment for secondary prevention of CAD according to the existing guidelines.

Inclusion to the study criteria: established diagnosis of CAD and age of 18 years old and older.

Exclusion from the study criteria: age greater than 80 years, cognitive disorientation and communicative disabilities or other severe somatic diseases, or inability to speak Lithuanian fluently.

Within three days of admission to the rehabilitation clinic all patients were evaluated for demographic and clinical characteristics, including New York Heart Association (NYHA) functional class, body mass index (BMI), hypertension, presence of chest angina and diabetes, history of $\mathrm{Ml}$ and previous interventional treatments for $C A D$, including percutaneous coronary intervention $(\mathrm{PCl})$ and coronary artery bypass graft (CABG) surgery. Patients were considered obese if their BMI was $\geq 30$ $\mathrm{kg} / \mathrm{m} 2$. During the same visit patients were evaluated for Type D personality using the DS14 questionnaire, ${ }^{5}$ for Big-Five personality traits using the 
Ten Item Personality Inventory (TIPI) ${ }^{22}$ and for symptoms of anxiety and depression using the Hospital Anxiety and Depression Scale (HADS). ${ }^{23}$ A subsample of 49 patients filled in the DS14 for the second time at the end of two weeks rehabilitation program.

\section{Assessment of Type D Personality}

The DS14 is a 14-item self-rating questionnaire that consists of two 7-item subscales that are designed to measure personality traits of NA and $\mathrm{SI}^{5}$ Each item is rated on a five point Likert-type scale from 0 (false) to 4 (true) with scores ranging from 0 to 28 on each subscale. Scores equal or greater than 10 on both DS14 subscales of NA and SI indicate Type $D$ personality. Lithuanian version of the DS14 was established using a standard doubleblind translation method. ${ }^{24}$

\section{Assessment of Anxiety and Depression}

The HADS is self-rating instrument consisting of two 7-item subscales of depression (HADS-D) and anxiety (HADS-A), which are designed to measure respective symptoms during the past week. ${ }^{23}$ Lithuanian version of the HADS was shown to be a reliable screening instrument in Lithuanian CAD patients. ${ }^{25,26}$ Each HADS item is rated from 0 to 3, with total scores in both subscales ranging from 0 to 21; higher score indicates more severe symptoms.

\section{Big-Five Personality Dimensions}

The TIPI is a 10-item self-rating instrument designed for assessment of Big-Five personality dimensions of Extraversion, Agreeableness, Conscientiousness, Emotional Stability and Openness. ${ }^{22}$ All items have a common stem of 'I see myself as' and consist of two descriptors that represent the same pole of Big-Five personality dimensions. For each personality dimension there are two items that represent opposite poles. Each item is rated on a 7-point Likert-type scale with possible choices ranging from 1 (disagree strongly) to 7 (agree strongly). Scores on each subscale range from 2 to 14 and higher scores indicate more pronounced personality trait. Translated Lithuanian version of the TIPI was used as in previous studies. $^{27}$

\section{Data Records}

Variables included in the data-set are presented in Table 1.
Table 1. Variables included in the dataset.

\begin{tabular}{|c|c|}
\hline Variables & Coding \\
\hline Age & years \\
\hline Gender & $\begin{array}{l}1=\text { Men, } \\
2=\text { Women }\end{array}$ \\
\hline NYHA class & $1=I, 2=I I, 3=I I I$ \\
\hline Hypertension & $0=$ No, $1=$ Yes \\
\hline Angina Pectoris & $0=$ No, $1=$ Yes \\
\hline Myocardial Infarction & $0=$ No, $1=$ Yes \\
\hline \multicolumn{2}{|l|}{ Previous treatments } \\
\hline $\mathrm{PCl}$ & $0=$ No, $1=$ Yes \\
\hline CABG & $0=$ No, $1=$ Yes \\
\hline Diabetes mellitus & $0=$ No, $1=$ Yes \\
\hline BMI & $\mathrm{kg} / \mathrm{m}^{2}$ \\
\hline $\mathrm{BMI} \geq 30$ & $0=$ No, $1=$ Yes \\
\hline DS14 - Type D scale & score \\
\hline HADS Anxiety subscales & score \\
\hline HADS Depression subscale & score \\
\hline HADS total & score \\
\hline TIPI & score \\
\hline
\end{tabular}

NYHA - New York Heart Association; BMI - Body mass index; $\mathrm{PCl}$ - percutaneous coronary intervention; $\mathrm{CABG}$ - coronary artery by-pass graft surgery; HADS Hospital Anxiety and Depression scale; TIPI - Ten-Item Personality Inventory.

\section{Use of the Dataset}

The study findings were used to prepare a publication investigating: (1) the validity of the Type D construct and its assessment with the DS14 in Lithuania; (2) the prevalence of Type D personality in Lithuanian patients with CAD; and (3) the association of Type $D$ personality with an increased vulnerability for anxiety and depression in these patients. $^{21,28}$

\section{Data Files}

The data described in this paper is presented in an openly accessible spreadsheet: "01205_TypeD_ Lithuanian_patients_with_CAD.xIs".

The file is available also in the Open Document Spreadsheet format.

\section{Acknowledgements}

The preparation of this manuscript was supported by the EU-funded project OpenScienceLink (Grant agreement \# 318652). 


\section{References}

${ }^{1}$ Bunevicius A, Stankus A, Brozaitiene J, Girdler SS, Bunevicius R. Relationship of fatigue and exercise capacity with emotional and physical state in patients with coronary artery disease admitted for rehabilitation program. Am Heart J. 2011 Aug;162(2):310-6. doi: 10.1016/j.ahj.2011.05.003.

2 Kent LK, Shapiro PA. Depression and related psychological factors in heart disease. Harv Rev Psychiatry. 2009;17(6):377-88. doi: 10.3109/106732 20903463333.

3 Rozanski A, Blumenthal JA, Davidson KW, Saab PG, Kubzansky L. The epidemiology, pathophysiology, and management of psychosocial risk factors in cardiac practice: the emerging field of behavioral cardiology. J Am Coll Cardiol. 2005 Mar 1;45(5):637-51. doi: 10.1016/j.jacc.2004.12.005.

4 Denollet J, Schiffer AA, Spek V. A general propensity to psychological distress affects cardiovascular outcomes: evidence from research on the type $D$ (distressed) personality profile. Circ Cardiovasc Qual Outcomes. 2010 Sep;3(5):546-57. doi: 10.1161/ circoutcomes.109.934406.

${ }^{5}$ Denollet J. DS14: standard assessment of negative affectivity, social inhibition, and Type D personality. Psychosom Med. 2005 Jan-Feb;67(1):89-97. doi: 10.1097/01.psy.0000149256.81953.49.

${ }^{6}$ de Jonge $P$, Denollet J, van Melle JP, Kuyper A, Honig $A$, Schene $A H$, et al. Associations of type-D personality and depression with somatic health in myocardial infarction patients. J Psychosom Res. 2007 Nov;63(5):477-82. doi: 10.1016/j.jpsychores.2007.06. 002.

7 Al-Ruzzeh S, Athanasiou T, Mangoush O, Wray J, Modine T, George S, et al. Predictors of poor mid-term health related quality of life after primary isolated coronary artery bypass grafting surgery. Heart. 2005 Dec;91(12):1557-62. doi: 10.1136/hrt.2004.047068.

${ }^{8}$ Smith OR, Michielsen HJ, Pelle AJ, Schiffer AA, Winter JB, Denollet J. Symptoms of fatigue in chronic heart failure patients: clinical and psychological predictors. Eur J Heart Fail. 2007 Sep;9(9):922-7. doi: 10.1016/j.ejheart.2007.05.016.

9 Williams L, O'Connor RC, Grubb N, O'Carroll R. Type $D$ personality predicts poor medication adherence in myocardial infarction patients. Psychol Health. 2011 Jun;26(6):703-12. doi: 10.1080/08870446.2010.488265.

${ }^{10}$ Spindler H, Pedersen SS, Serruys PW, Erdman RA, van Domburg RT. Type-D personality predicts chronic anxiety following percutaneous coronary intervention in the drug-eluting stent era. J Affect Disord. 2007 Apr; 99(1-3):173-9. doi: 10.1016/j.jad.2006.09.009.
${ }^{11}$ Martens EJ, Kupper N, Pedersen SS, Aquarius AE, Denollet J. Type-D personality is a stable taxonomy in post-MI patients over an 18-month period. J Psychosom Res. 2007 Nov;63(5):545-50. doi: 10.1016/ j.jpsychores.2007.06.005.

${ }^{12}$ Denollet J, Pedersen SS, Vrints CJ, Conraads VM. Usefulness of type $D$ personality in predicting five-year cardiac events above and beyond concurrent symptoms of stress in patients with coronary heart disease. Am J Cardiol. 2006 Apr 1;97(7):970-3. doi: 10.1016/ j.amjcard.2005.10.035.

${ }^{13}$ Denollet J, Conraads VM. Type D personality and vulnerability to adverse outcomes in heart disease. Cleve Clin J Med. 2011 Aug;78 Suppl 1:S13-9. doi: 10.3949/ccjm.78.s1.02.

${ }^{14}$ Bergvik S, Sorlie T, Wynn R, Sexton H. Psychometric properties of the Type D scale (DS14) in Norwegian cardiac patients. Scand J Psychol. 2010 Aug;51(4):33440. doi: 10.1111/j.1467-9450.2009.00793.x.

${ }^{15}$ Grande G, Romppel M, Glaesmer H, Petrowski K, Herrmann-Lingen C. The Type D scale (DS14): norms and prevalence of Type $D$ personality in a populationbased representative sample in Germany. Personality and Individual Differences. 2010;48:935-9. doi: 10.1016/j.paid.2010.02.026.

${ }^{16}$ Howard S, Hughes BM. Construct, concurrent and discriminant validity of Type $D$ personality in the general population: associations with anxiety, depression, stress and cardiac output. Psychol Health. 2012;27(2): 242-58. doi: 10.1080/08870446.2011.603423.

${ }^{17}$ Spindler $H$, Kruse C, Zwisler AD, Pedersen SS. Increased anxiety and depression in Danish cardiac patients with a type $D$ personality: cross-validation of the Type D Scale (DS14). Int J Behav Med. 2009;16(2):98107. doi: 10.1007/s12529-009-9037-5.

${ }^{18}$ Lim HE, Lee MS, Ko YH, Park YM, Joe SH, Kim YK, et al. Assessment of the type $D$ personality construct in the Korean population: a validation study of the Korean DS14. J Korean Med Sci. 2011 Jan;26(1):116-23. doi: 10.3346/jkms.2011.26.1.116.

${ }^{19}$ Pedersen SS, Yagensky A, Smith OR, Yagenska O, Shpak V, Denollet J. Preliminary evidence for the crosscultural utility of the type $D$ personality construct in the Ukraine. Int J Behav Med. 2009;16(2):108-15. doi: 10.1007/s12529-008-9022-4.

${ }^{20}$ Yu DS, Thompson DR, Yu CM, Pedersen SS, Denollet J. Validating the Type $D$ personality construct in Chinese patients with coronary heart disease. J Psychosom Res. 2010 Aug;69(2):111-8. doi: 10.1016/ j.jpsychores.2010.01.014.

${ }^{21}$ Bunevicius A, Staniute M, Brozaitiene J, Stropute D, Bunevicius R, Denollet J. Type D (distressed) personality and its assessment with the DS14 in Lithuanian patients 
with coronary artery disease. J Health Psychol. 2013 Sep;18(9):1242-51. doi: 10.1177/1359105312459098.

${ }^{22}$ Gosling SD, Rentfrow PJ, Swan WBJ. A very brief measure of the Big-Five personality domains. Journal of Research in Personality. 2003;37(6):504-28. doi: 10.1016/s0092-6566(03)00046-1.

${ }^{23}$ Zigmond AS, Snaith RP. The hospital anxiety and depression scale. Acta Psychiatr Scand. 1983 Jun;67(6): 361-370. PMID: 6880820.

${ }^{24}$ Staniute M, Bunevicius R. Evaluation of Type D personality using the DS14 questionnaire. Biological psychiatry and psychopharmacology. 2011;13:36-7. http://biological-psychiatry.eu/wpcontent/uploads/2014/06/BPP_2011_T13_Nr1.pdf.

${ }^{25}$ Bunevicius A, Brozaitiene J, Stankus A, Bunevicius R. Specific fatigue-related items in self-rating depression scales do not bias an association between depression and fatigue in patients with coronary artery disease.
Gen Hosp Psychiatry. 2011 Sep-Oct;33(5):527-9. doi: 10.1016/j.genhosppsych.2011.06.009.

${ }^{26}$ Bunevicius A, Staniute M, Brozaitiene J, Bunevicius R. Diagnostic accuracy of self-rating scales for screening of depression in coronary artery disease patients. J Psychosom Res. 2012 Jan;72(1):22-5. doi: 10.1016/ j.jpsychores.2011.10.006.

${ }^{27}$ Bunevicius A, Katkute A, Bunevicius R. Symptoms of anxiety and depression in medical students and in humanities students: relationship with big-five personality dimensions and vulnerability to stress. Int J Soc Psychiatry. 2008 Nov;54(6):494-501. doi: 10.1177/ 0020764008090843.

${ }^{28}$ Bunevicius A, Brozaitiene J, Staniute M, Gelziniene V, Duoneliene I, Pop VJ, et al. Decreased physical effort, fatigue, and mental distress in patients with coronary artery disease: importance of personality-related differences. Int J Behav Med. 2014 Apr;21(2):240-7. doi: 10.1007/s12529-013-9299-9. 